\title{
Studies on Juice Quality Obtained from Pomegranate and Various Vegetables Additions
}

\author{
Anamaria POP, Sevastița MUSTE, Crina MUREȘAN, Simona JULA \\ Faculty of Food Science and Technology, University of Agricultural Sciences and Veterinary Medicine, Faculty of \\ Agriculture, 3-5 Mănăștur street, 3400, Cluj-Napoca, Romania \\ crinacarmen@gmail.com
}

Bulletin UASVM Food Science and Technology 71(1) / 2014

ISSN-L 2344-2344; Print ISSN 2344-2344; Electronic ISSN 2344-5300

\begin{abstract}
Nowadays, the interest in antioxidants, mainly present in fruits and vegetables, has prompted research in the field of commercial beverages. Taking into account new requirements to improve the quality of feeding behaviour by getting juices without added sugar, the consumer health benefits and high organoleptics properties, it was decided to study the correlation quality of raw pomegranates with other vegetables such as celery, carrot and sharon fruit in order to obtain pomegranate juice with vegetable additions. The vegetable raw materials were chosen in order to improve the quality and organoleptic properties of the pomegranate juice with vegetable additions by optimizing the "in-house" method, to obtaining a stable formulation. The main objectives of the study were characterization of raw and addition materials, studied by psycho-chemical analysis, evaluating of the antioxidant capacity of 4 types of pomegranate juice with additions in different proportions, establish the best type of mixture juice. Consumer preference was established in sensory analysis based on hedonic test with 9 point scale, the type of juice with additions with the following concentrations: pomegranate $50 \%$, Sharon $10 \%$, celery $30 \%$, carrot $10 \%$. Positive correlations were performed between antioxidant capacity and type of juice preferred by consumers.
\end{abstract}

Keywords: Pomegranate, celery, natural, sharon, vitamins, antioxidants, sensory analysis.

\section{INTRODUCTION}

Fruit juice is the liquid unfermented but fermentable obtained from the edible part of the fruit sufficiently ripe fruit and fresh fruit or maintained in good condition by appropriate means, including surface treatments applied after harvest in accordance with the applicable provisions of the Codex Alimentarius.(www. codexalimentarius.org/standards)

The juice is prepared by suitable processes, which maintain the physical, chemical , organoleptic, nutritional and essential characteristics of the fruit from which it comes. The juice may be cloudy or clear and may have volatile aromatics and flavor components. In terms of quality juice, it must have color, odor and taste characteristic type of fruit comes from. The authenticity of the product is important to maintain the physico -chemical, organoleptic and nutritional properties of the fruit from which it comes. The pomegranate is one of the important dietary sources of antioxidant phenolics (Murthy et al. (2002) and Ozgen et al. (2008). Powerful antioxidant capacity of pomegranate juice has been reported by many scientists using multiple assay systems in vitro. This ability is largely due polofenolic constituents. Thus, it was shown that pomegranate juice has both a higher total polyphenols and antioxidant activity greater than other juices frcvent consumed insclusiv grapes, blueberries, oranges or apples. Ascorbic acid content of commercial fruit juices ranged from 2.4 to $43 \mathrm{mg} / 100 \mathrm{ml}$ of juice (Kabasakal D et al., 2000). Influence of processing and storage conditions on anthocyanin stability and antioxidant 
activity of clarified and cloudy juices from pomegranate variety was studied in 2013 by Salud Vegara et al. and the results showed that hurdle technology (heating plus refrigeration) may help to reduce anthocyanin degradation in pasteurized pomegranate juice, avoiding a dramatic impact on its colour and preserving the beneficial effects of this specific bioactive compounds on human health.

\section{MATERIALS AND METHODS}

The research has been carried outat the Faculty of Food Science and Technology, Laboratory of Food Quality Control to achieve control part of the products. All raw materials used in these experiments have been purchased from markets of specialized stores. The study was performed based on pomegranates (Punica granatum), celerys (Apium graveolens L.), carrots (Daucus carota) and Sharon fruits (Diospyros lotus). The research was conducted around of the four major objectives. The first goal was to establishing main physicochemical parameters of raw materials studied. To achieve this goal has been determined the $\mathrm{pH}$, moisture content, vitamin $\mathrm{C}$ content, total sugars and antioxidant capacity. All determinations were performed according to current standards of food quality control (Tab. 1). The second goal was to establishing the optimal intake of pomegranate juice with admixtures, based on physico-chemical analysis (Tab. 2). The fruits juices were obtained directly by mechanical extraction processes. The third goal was to determination of physicochemical parameters and antioxidant capacity of the four prototypes of juice established. The last goal was to evaluation using sensory analysis, the prototype of pomegranate juice with admixtures, preferred by consumers. In this case, the aim pursued by sensory analysis is to test consumer preferences for a possible placing of the market of new products made. In this sense, chosen method was the hedonic scale. This method is not to perform an analysis to determine the precise sensory qualities of the product but involves the selection of preferred sample of a certain number of samples representing different types of the same product. For the examination samples was used in a number of 80 tasters, teachers and students from the Faculty of Food Science and Technology, University of Agricultural Sciences and Veterinary Medicine Cluj-Napoca.

\section{RESULTS AND DISCUSSIONS}

In terms of raw material taken to be studied like pomegranate, celery, carrot and sharon fruit, correspond to organoleptic and physico-chemical parameters. In terms of color and appearance, all the vegetables smell is pleasant specific for each

Table 1. Quality parameters results

\begin{tabular}{lccccc}
\hline \multirow{2}{*}{$\begin{array}{c}\text { Vegetable Raw } \\
\text { Materials }\end{array}$} & $\mathrm{pH}$ & $\begin{array}{c}\text { Moisture content } \\
(\%)\end{array}$ & $\begin{array}{c}\text { Ascorbic acid } \\
\text { (mg./ 100 g) }\end{array}$ & $\begin{array}{c}\text { Total sugars } \\
\text { (Brix) }\end{array}$ & $\begin{array}{c}\text { Antioxidant } \\
\text { capacity, } \\
\mathrm{KMnO}_{4} \text { (sec.) }\end{array}$ \\
\cline { 2 - 6 } Pomegranate & 2 & 71.55 & 7.04 & 3.07 & 40 \\
\hline Celery & 6 & 89.58 & 12 & 3.80 & 30 \\
\hline Carrot & 6 & 86.02 & 6.16 & 2.05 & 110 \\
\hline Sharon & 7 & 91.02 & 7.04 & 6.82 & 150 \\
\hline
\end{tabular}

Table 2. Prototypes obtained from mixture of juices

\begin{tabular}{ccccc}
\hline Samples & $\begin{array}{c}\text { Pomegranate } \\
\text { Juice (\%) }\end{array}$ & $\begin{array}{c}\text { Celery } \\
\text { Juice (\%) }\end{array}$ & $\begin{array}{c}\text { Carrot } \\
\text { Juice (\%) }\end{array}$ & $\begin{array}{c}\text { Sharon } \\
\text { Juice (\%) }\end{array}$ \\
\hline 1 & 60 & 10 & 10 & 20 \\
\hline 2 & 50 & 20 & 20 & 10 \\
\hline 3 & 50 & 20 & 10 & 20 \\
\hline 4 & 50 & 30 & 10 & 10 \\
\hline
\end{tabular}


without the smell of mold, musty or other foreign smell and specific taste.

After analyzing the $\mathrm{pH}$ of all the samples, we observe that vegetables (celery and carrot) have a $\mathrm{pH}$ of 6, and pomegranate fruit and Sharon have $\mathrm{pH}$ located at the two extremes, that help to obtain a balance in the finished product between alkalinity of Sharon fruit and acidity of pomegranate. As regards the moisture content, Sharon fruit registers a higher moisture $(91.02 \%)$ and pomegranates having the lowest value $(71.55 \%)$, because of the high content of seeds. Ascorbic acid has the highest value in celery $(12 \mathrm{mg} . / 100 \mathrm{~g}$ ) followed by pomegranate and sharon fruit (7.04) and the lowest value is register in carrot $(6.16 \%)$. The highest sugar content in the fruit it stands out from Sharon followed by celery, pomegranate and lowest in sugar content it has carrots. Followed for discoloration of $\mathrm{KMnO} 4$ solution after addition of a set of evidence, as find that celery has recorded the shortest time fading, which proves that it has a higher antioxidant capacity as compared to samples analyzed, followed by pomegranate, carrot and Sharon fruit, as can be seen in Table1.

Establishing optimal intake between pomegranate juice and other juices used as addition to

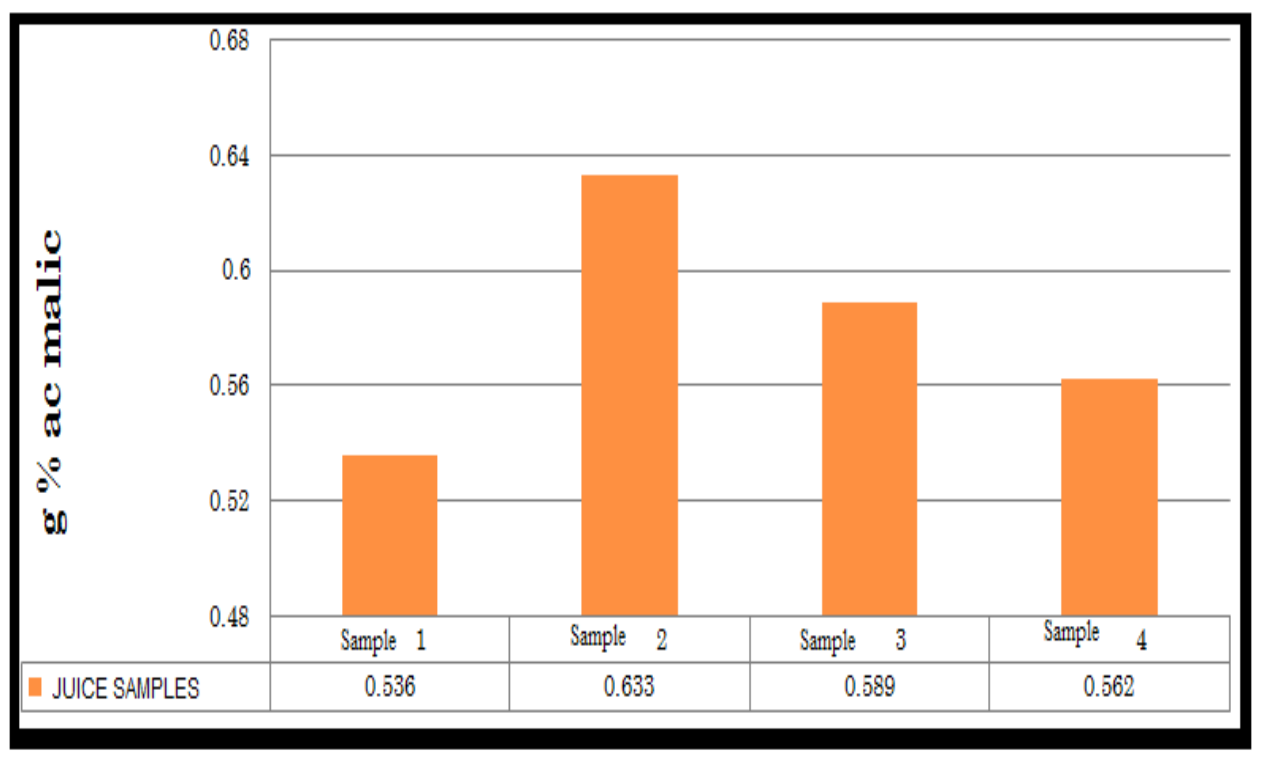

Fig. 1. Acidity of mixture juices

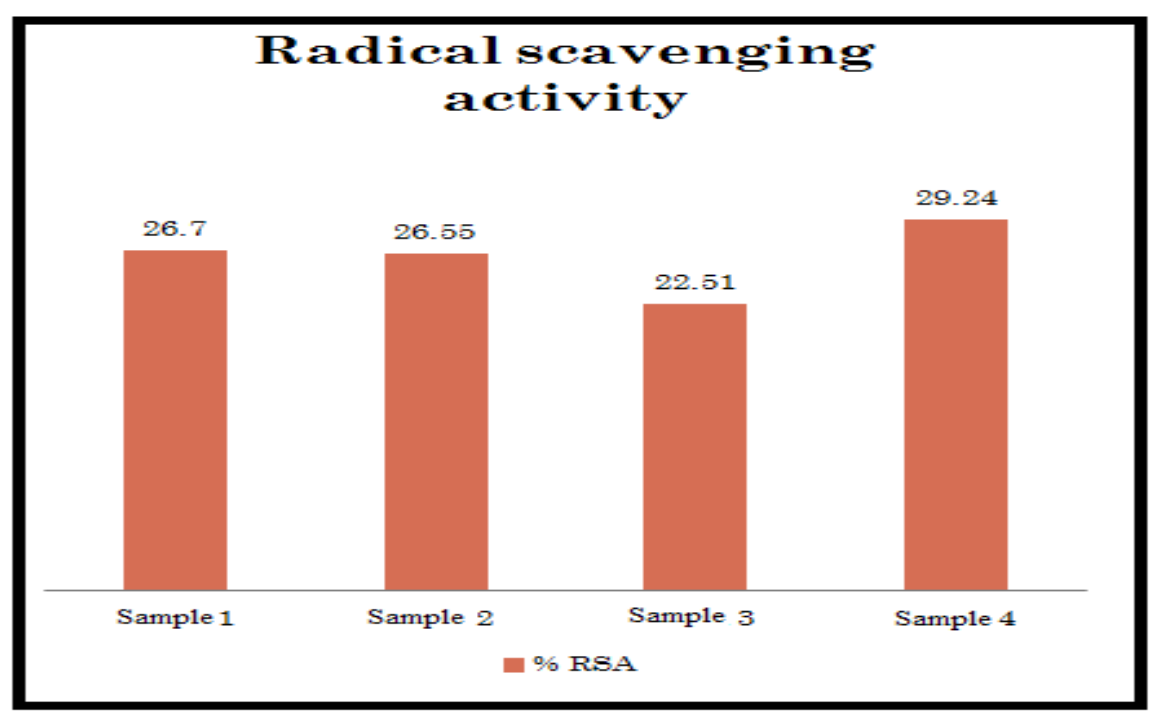

Fig. 2. Antioxidant activity DPPH method 
obtain prototypes based pomegranate juice, was achieved based on physicochemical analysis on fruits and vegetables studied, depending on their properties.

In terms of view of the acidity of the juice obtained prototypes, we note that among the four samples is very small differences recorded, being included in a range between 0.536 and $0.633 \mathrm{wt} \%$ malic acid (Fig. 1). Higher acidity is remarkable to sample 2 consists of $50 \%$ pomegranate juice, celery juice $20 \%$, carrot juice $20 \%$ and sharon juice $10 \%$ (Fig. 3). It was investigated the antioxidant capacity by the scavenging activity against 1,1-diphenyl-2-picrylhydrazyl (DPPH). As seen in the graph 2 , the sample number 4 has the highest antioxidant activity is explained by the fact that, according to previous determinations celery juice recorded the highest antioxidant activity, and this sample contains a higher intake of celery than the rest of the samples.

After analyzing the samples, found that the highest value of absorbance at $515 \mathrm{~nm}$ to Name Rank for sample number 3, which shows that this sample has the lowest radical scavenging activity capture of $22.51 \%$, which was evidenced by analyzing the 4 samples of juice (Fig. 2).

The highest activity of the free radicals was recorded for sample number 4 , with a value of 29.24 percent, as this sample contains the highest percentage of celery juice in comparison with other samples. The first and the second sample, is remarkable as having a similar value on the activity of the free radicals.

Hedonic test results are influenced by the psychological effect on consumers. This test not only allows you to choose the preferred sample,

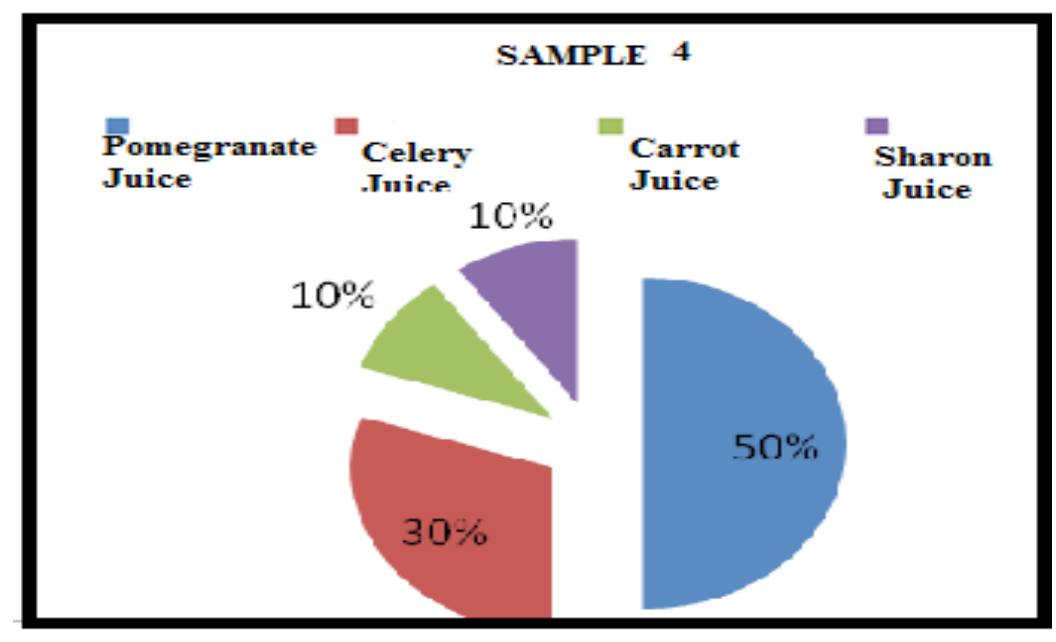

Fig. 3. The ratio of pomegranate juice and additions of vegetable juices

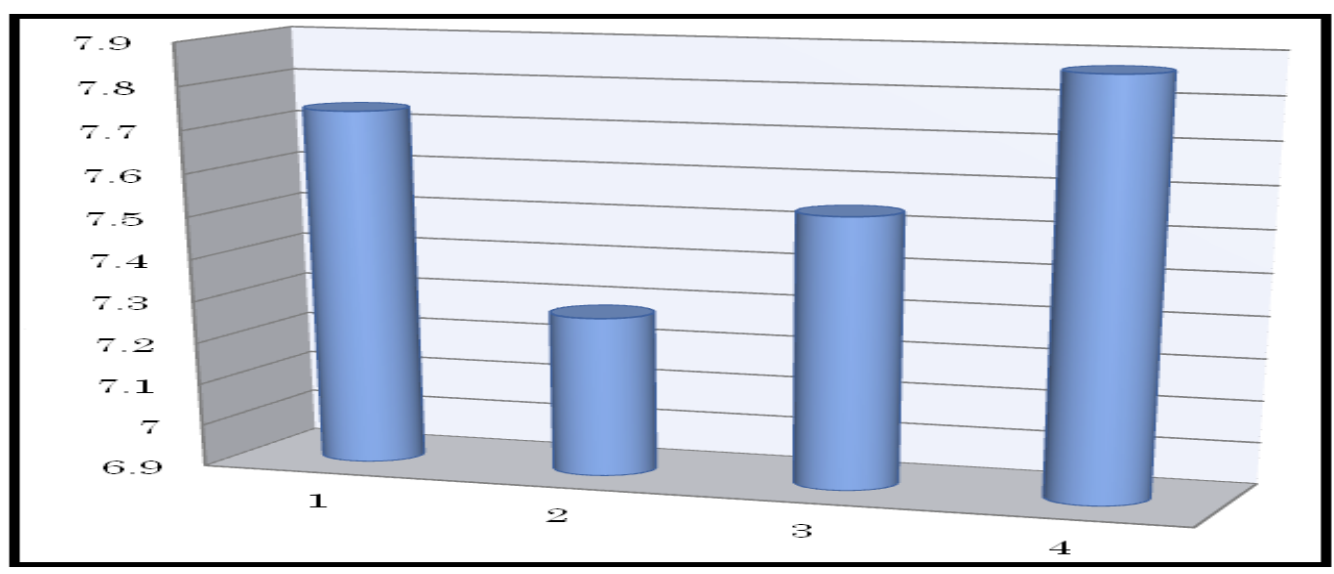

Fig. 4. General score evaluation of 9 - point hedonic scale 
but measured the degree preferably through the 9 steps, distributed as follows: the first four (1-4) are negative sensations, and the other 4 (6-9), repre positive feelings. 5th step of the means sensation of-regardless. (Pery et al., 1997). Records were processed statistically.

After consumer preference testing, it was found that the sample number 4 consisting of $50 \%$ pomegranate juice, $30 \%$ celery juice, $10 \%$ carrot juice and $10 \%$ sharon juices, it is preferred by the consumer (Fig. 4).

\section{CONCLUSION}

In the present research study, was demonstrated that valorification of vegetables like celery, carrot, Sharon can be suitable in the beverage industry.

There was a positive correlation between physicochemical parameters and consumer preference (taste balanced between acidity and sugars )

Following the quality control of fruit and vegetables performed, we find that the addition to getting a pomegranate based juice, is beneficial, because it improves the organoleptic and fizcochemical prototype of juice obtained. Thus, to obtain pomegranate juice with the addition of other fruits and vegetables, justify adding celery juice due to the high antioxidant capacity that it has, and because of the high content of vitamin $C$.

Addition of Sharon fruit juice is justified because of alkalinity, which favours creating a balance in the type of juice in terms of its acidity. Also, Sharon fruit juice helps to increase the energy value of products by the fact that is high intake of carbohydrates.

Regarding the addition of carrot juice, it improves the organoleptic and sensory properties of the product.

It has been found that Sharon, celery and carrots were used as the additions improved the quality and organoleptic properties of the pomegranate with various vegetables juice by optimizing the "in-house" for obtaining a stable formulation and colloidal touch.

\section{REFERENCES}

1. Karadag, A. et al. (2009). "Review of Methods to Determine Antioxidant Capacities" Food Anal.Methods, 2: 41-60.

2. Muste, S. and Muresan, C. (2011)."Controlul calitatii materiilor prime de origine vegetala"- Caiet de lucrari practice, AcademicPres, Cluj-Napoca.

3. Vegara, S. et al. (2013). Approaches to understanding the contribution of anthocyanins to the antioxidant capacity of pasteurized pomegranate juices, 141(3):1630-1636.

4. Murthy, C. et al. (2002). Studies on antioxidant activity of pomegranate (Punica granatum) peel extractusing invivo models, Journal of Agriculture and Food Chemistry, 50:4791-4795.

5. Ozgen, M. et al. (2008). Chemical and antioxidant properties of pomegranate cultivars grown in Mediterranean region of Turkey, Food Chemistry, 111: 703-706.

6. Kabasakal, V.D. et al. (2000). Ascorbic acid content of commercial fruit juices and its rate of loss upon storage, Food Chemistry, 70(3): 325-328.

7. http://www.codexalimentarius.org/standards/en/ 